Revista de Antropología Social

ISSN: 1131-558X

https://dx.doi.org/10.5209/raso.65620

\title{
Investigando Economías de Vidas que puedan ser vividas
}

Santamaría, Enrique; Yufra, Laura C. y de la Haba, Juan (Eds.). 2018. Investigando economías solidarias (acercamientos teórico-metodológicos). Barcelona: ERAPI.

El fin del mundo que conocíamos está llegando. No se alarmen, es un final largamente anunciado y largamente, también, ignorado. El cambio climático, la crisis de los cuidados, la emergencia migratoria, la escasez de recursos naturales, la crisis de un capitalismo que se ha tratado de lamer las heridas a través de una austeridad, todo ello nos ha colocado en el Estado de Malestar, pues claramente no podemos seguir hablando de Estado de Bienestar. El fin del mundo que conocíamos lo aventuraba ya la ciencia ficción hace años (recuerden la acogida que tuvo Silent Spring en 1962 de Rachel Carson). Habitamos la distopía. Escribía lúcidamente Úrsula K. Le Guin que "la ciencia ficción tiene precisamente como función cuestionar la manera de vivir y pensar, creando nuevos caminos a raíz de la dialéctica, la imaginación y la abolición del capitalismo" (1989: 155). Algunos teóricos hablan de su escritura como una suerte de "antropología utópica" y es que la creación debe ajustarse al presente pero también forjar caminos alternativos hacia el futuro. En este sentido la ciencia ficción camina de la mano de la ciencia.

El fin del mundo que conocíamos nos interpela directamente a los investigadores sociales pues ya no se trata de describir un locus typicus sino de adaptar también la mirada, es decir, la metodología y su marco teórico, al cambio, al Estado en crisis, al movimiento, a los nuevos desarrollos organizativos, formales e informales, que gestionan esta crisis. Hemos de avanzar. Por ello resulta tan estimulante este volumen que editan Enrique Santamaría, Laura C. Yufra y Juan de la Haba en el que, como resultado de diversas investigaciones que desde 2014 han realizado en el Institut Català d'Antropología y su derivado colectivo ERAPI, proponen una "socioantropología" (Olivier De Sardan, 1997) que analice las nuevas economías solidarias desde un prisma epistemológico ad hoc, una "ecología de saberes" interdisciplinares, inconclusos y en construcción "en relación a los procesos de producción, distribución, consumo y cuidados que aspiran a ser alternativos a los propios de las economías capitalistas" (2018:6). No en vano la obra se titula Investigando Economías Solidarias, y ponemos el énfasis en su primera palabra, gerundio en primera conjugación, siendo su valor claramente modal, instrumental. Es decir, torna el verbo investigar en un verbo en movimiento, complemento de modo, complemento de medio que enuncia ya la intención del texto, ajustarse, moverse junto a, acompañar epistemológicamente algo que muta, la economía, el clima, la esfera reproductiva.

Este libro recorrerá toda esta constelación de problemáticas a través de sus catorce colaboraciones estructuradas en cinco partes: Preliminares-Introducciones-Continuidades-Persistencias-Clausuras. Hacemos de nuevo hincapié en ese movimiento orgánico que pareciera acompañar en todo momento esta obra y que ayuda a enhebrar el existente hiato, ampliamente confrontado en este volumen, entre epistemología y 
metodología (Olivier De Sardan, 2015). Resulta estimulante que los autores no eludan debates a la hora de delimitar conceptos complejos como "economías solidarias" rescatando, así mismo, denostadas categorías como "cooperación”, cuestionando el "desarrollo" y aportando en todo momento un punto de vista amplio y crítico en este difícil contexto crísico ${ }^{1}$. Son, por tanto, diversas las tensiones epistémicas que recorren esta obra y que van repiqueteando a lo largo de todo el libro, pues, como hemos señalado, no está organizado por bloques temáticos sino por estratos (preliminares-introducciones-continuidades-persistencias-clausuras), que hacen que todas las categorías analíticas salgan una y otra vez a la superficie, cada vez más ricas en matices. Los ejes fundamentales son tres y forman una bella trenza que conforma una obra de gran reflexión, profundidad y amplio espectro social: la economía feminista, la economía social y solidaria y los aspectos hermenéuticos, metodológicos, epistemológicos e ideológicos a los que, como investigadores, debemos hacer frente en su estudio.

La primera parte, Introducciones, abre con el texto de Laura Collin sobre el necesario giro copernicano que supone invertir la lógica del capital por la lógica reproductiva. Al de Collin suceden los textos de Daniela Osorio-Cabrera, Jordi BonetMartí, y Alba Shirley Tamayo que, en el ulterior apartado de Persistencias, continúan reflexionando sobre la intersección entre economía solidaria y feminismos, un asunto central en la investigación de las últimas décadas desde que ya en los años setenta comenzaran a advertirse las contradicciones entre cuidados y capital en su declinación comunitaria (Dalla Costa y James, 1972). Collin se pregunta si es posible avanzar hacia nuevos modelos de economía que no transiten por la "lógica de la reproducción ampliada del capital” (2018:26), mientras que Osorio-Cabrera incide en la categoría de vida vivible que ya planteara Butler para fondear en las relaciones de interdependencia e intrínseca vulnerabilidad y precariedad (Butler, 2010). Por su lado, Jordi Bonet-Martí rescata la, a nuestro entender, maravillosa obra crítica de Karl Polanyi, situando su lectura más allá del modelo clásico, neoclásico o incluso marxista de la economía, para hibridarlo con las economías feministas, al entender el clásico "encastramiento" - embeddeness - que proponía Polanyi al hablar de la economía como categoría incrustada en la sociedad, cuyas tres formas de integración - reciprocidad, redistribución e intercambio - podrían remitirnos de manera tangencial a las economías críticas sociales y feministas. En la misma senda, en el apartado de Conclusiones encontramos a Eduardo Enrique Aguilar y Héctor David Sotomayor que, también desde Polanyi, se manifiestan "en sentido contrario a la escisión de la economía de las otras esferas de la vida" (2018:145), pues en la hegemonía neoliberal, volvemos a trenzar a Bonet-Martí, "un proyecto crítico tiene que tener por objetivo reincrustar la economía en la sociedad" (2018:115), proceso solo plausible a través de los desarrollos divergentes de la economía solidaria y feminista.

¿Pero es posible reincrustar esta categoría como alternativa a la sociedad de mercado? ¿Son posibles las vidas vivibles si nos atenemos al binomio producción/reproducción?, ¿es posible hablar de economía moral o política de afectos en este moribundo capitalismo? Los autores arriban por distintas vías a una conclusión afirmativa

Utilizamos el término "crísico" que Enrique Santamaría reivindica en la línea abierta por pensadores como el sociólogo francés Edgar Morin (2014), al hablar de un pensamiento no solo crítico, sino crísico, pues deriva, emerge, de un contexto de crisis y eso le otorga unas características propias. En este sentido, desde hace años, Santamaría reivindica que es necesaria una socioantropología "crítica, crísica y creativa" (Santamaría, 2002:44). 
al plantear tejidos sociales más extensos, más sólidos, redes de economía incrustada basada en una solidaridad vinculada a la reciprocidad, que necesariamente converja en la constatación de un "sujeto comunitario" (2018: 26) y unas "comunidades afectivas" (2018: 104), que mantengan el valor de uso sobre el valor de cambio y estén basadas en la visibilización de otros modos de producción y reproducción conducentes a un otro común que permita la lógica reproductiva de estas vidas vivibles. En este sentido, se sitúan en el mismo eje que otras investigadoras como Cristina Vega y Raquel Martínez (2018) o Yayo Herrero (2019) que en los últimos años continúan denunciando la falacia de la individualidad, marcando la necesidad de colocar la vida en el centro y de reconocernos como seres ecodependientes e interdependientes.

Pero ¿cómo implementar este nuevo marco epistemológico a la hora de investigar estas nuevas formas de producción y reproducción?, ¿qué implica la categoría analítica de economía social y solidaria?, ¿están nuestras prácticas y teorías subsumidas en la última transformación epistémica del capitalismo? Algunas de estas preguntas atraviesan continuamente este libro que, recordemos, se organiza en estratos lúcidamente trenzados, ofreciendo sugerentes mechones teóricos que nos conducen a nuevas profundidades epistémicas, desde su inicio en Introducciones, pasando por sus Continuidades, Persistencias y Clausuras - ¿es posible clausurar esta zanja abierta?-. Buen ejemplo de ello se persona en el apartado de Introducciones en el que Jesús Sanz, Gaël Carrero y Gema Alcañiz señalan algunas carencias de nuestros aparatos metodológicos hasta la confrontación que en el apartado de Clausuras realizan Aguilar y Sotomayor sobre la dicotomía desarrollo-subdesarrollo dentro de las economías solidarias. Esta estructura crítica pretende localizar los pros y contras de esta nuestra investigación socioantropológica que dista mucho de ser aporética. En base a esta premisa, Sanz, Carrero y Alcañiz ofrecen un texto en el que por un lado revisan las actuales líneas de investigación vinculadas a la economía social y solidaria señalando sus principales aportaciones y, por otro, indagan en algunos de sus sesgos, límites, contradicciones y dilemas. Los autores entienden que precisamente será la perspectiva etnográfica la que mediante su "microanálisis de la realidad" (2018:33) podrá detectar las incoherencias entre episteme, doxa y praxis que se ponen en juego en las diversas economías solidarias. Por ello es desde el estudio de casos de iniciativas de economía social y solidaria desde el que se arroja un resultado que muestra la difícil comunión entre discurso versus acción, señalando así la hibridación y articulación de las diversas lógicas económicas (tanto capitalistas como no-capitalistas) que nos impediría hablar de categorías exentas. Por ello ponen el foco en el análisis de las prácticas desde la perspectiva etnográfica como un instrumento que nos ayude a entender las múltiples y cambiantes realidades de la economía solidaria.

La conversación es fundamental, opina Tamayo Arango, al estudiar en el apartado de Persistencias, el caso del movimiento social de las Madres de la Candelaria, en Colombia. Mujeres que se manifiestan desde los años 90 contra las numerosas desapariciones forzadas, secuestros y homicidios en el marco del conflicto armado colombiano. Conversar con estas mujeres cuyas "narraciones tejen la interdependencia del entramado de experiencias" (2018:126) le ha permitido a Tamayo Arango encontrar la hibridación del mundo privado con el mundo público a través de esta potente asociación de mujeres vulnerables que, mediante su lucha trashumante, conquista espacios físicos, políticos y simbólicos gestando otro tipo de lógicas pues "construyen una economía otra" (2018:126) desde la reflexión, la reivindicación y los afectos. 
Es en este mismo sentido en el que desde Uruguay -ellos localizan su saber ya desde el título de la colaboración- nos llega el texto de Anabel Rieiro, Clara Betty Weisz y Natania Tommasino, que abogan no solo por una necesaria revisión metodológica sino por supuesto, y con marcado cariz decolonial, por una ruptura epistemológica que nos ayude a encontrar "epistemologías otras para las economías alternativas" (2018:43). Especialmente sugerente es que afronten el reto investigador también desde la propia decolonización del saber que hallan, como es lógico y asumido trágicamente por nuestra comunidad académica, adherido a la lógica del capital. Lógica del capital de la que no bebe siempre un "saber socialmente productivo" y del que hablan en el último apartado, Clausuras, Patricia Evangelina Patagua y Sabrina Zinger que sitúan su investigación en dos movimientos sociales en la provincia argentina de Jujuy ("Barrios de Pie" y "Tupaj Katari"). A través del trabajo de Patagua y Zinger - recordemos la importancia que en este libro se otorga al microanálisis etnográfico- logramos comprender la emergencia popular de un saber que estas experiencias alternativas demandan, cursando así como espacios de disrupción no solo económica sino por supuesto epistémica. Es a través del estudio de estos alternativos movimientos sociales como las autoras desarrollan la categoría de "saberes alternativos" que se gestarían en los escenarios de deconstrucción de hegemonías e individualidades y en la creación de colectividades apuntaladas, en su mayoría, en tres fascinantes planos: "la formación de subjetividades rebeldes, los vínculos entre los sujetos y los proyectos políticos de los movimientos sociales y las relaciones con el conjunto de la sociedad de la que forman parte" (2018:161). Esta formación de subjetividades rebeldes a través de los diversos grupos de saberes alternativos que Patagua y Zinger delimitan no es, de nuevo, una categoría exenta, aséptica, invulnerable, sino en continua lucha con la categorización de saberes hegemónicos y amamantados por el capital. Lo que nos coloca en el límite de nuevo de la incoherencia entre episteme, doxa y praxis que llevamos observando a lo largo de todo el libro, en esta emergencia de economías sociales y solidarias que nos arroja, como investigadores sociales, al desafío de acotarlas, observarlas, medirlas, teorizarlas, localizando sus carencias, sus estructuras, sus categorías, sus reglas. ¿Es esto posible o acabaremos la lectura de este completo y lúcido libro como Sísifo? Sin duda es un reto, un reto que los autores reconocen, señalan y acotan. Todo un paso a nivel epistemológico y también metodológico pues también aportan un saber necesario, como son las reflexiones particulares que María di Masso ofrece al hablar de las dificultades del trabajo de campo en el acceso, los muestreos, las comparativas, de su investigación en curso. Algo que también aporta Georgina Rosell al plantearnos la metodología de su estudio concreto en el entorno del cooperativismo en Barcelona y su correlación positiva con el incremento de tensiones ideológicas. Algo también estudiado por Rafael Tarifa que nos habla de la fluidez de las nuevas economías en su renovada crítica al capitalismo.

Todos estos estudios de caso que recoge este volumen sirven sin duda como andamiaje práctico mediante el que tender puentes entre la epistemología y la metodología para movernos al son de nuestros objetos de estudio: las economías sociales, solidarias y feministas que han supuesto en las últimas décadas una necesaria alternativa a las lógicas de mercado y producción que pronuncia el capital. Por ello, considero la lectura de este libro tan necesaria y estimulante, porque, como dijimos ya desde su título, se gesta en gerundio y es en ese gerundio en el que debemos situarnos, en 
el continuo movimiento, la mejora, la crítica y la reacción reflexionada a este panorama crísico. Investigando. Investigando para estudiar y ayudar a engendrar Vidas que puedan ser vividas.

Sofía Ugena Sancho Departamento de Antropología Social y Cultural (Facultad de Filosofía, UNED) sof.ugena@gmail.com

\section{Bibliografía}

Butler, Judith (2010). Marcos de guerra. Las vidas lloradas. Madrid: Paidós.

Dalla Costa, Mariarosa; James, Selma (1972). El poder de la mujer y la subversión de la comunidad. México: Siglo XXI.

Herrero, Yayo (2019). La vida en el centro. Voces y relatos ecofeministas. Madrid: Libros en Acción

Le Guin, Úrsula K. (1989). The Language of Night. Nueva York: Harper Collins.

Morin, Edgar (2014). La Méthode 4. Les idées. Paris: Seuil.

Olivier De Sardan, Jean-Pierre (1997). Anthropologie et développement. Paris: Karthala.

Olivier De Sardan, Jean Pierre (2015). Epistemology, Fieldwork, and Anthropology. Palgrave Macmillan US.

Santamaría, Enrique (2002). La incógnita del extraño. Una aproximación a la significación sociológica de la "inmigración no comunitaria". Barcelona: Anthropos.

Vega, Cristina; Martínez, Raquel. (Eds.) (2018). Cuidado, comunidad y común. Madrid: Traficantes de Sueños. 